\title{
Intervention effects on dietary intake among children by maternal education level: results of the Copenhagen School Child Intervention Study (CoSCIS)
}

\author{
Britt W. Jensen ${ }^{1,2,3 *}$, Lene M. von Kappelgaard ${ }^{4}$, Birgit M. Nielsen ${ }^{5}$, Ida Husby ${ }^{6}$, Anna Bugge ${ }^{2}$, \\ Bianca El-Naaman ${ }^{2}$, Lars B. Andersen ${ }^{2,7}$, Ellen Trolle ${ }^{8}$ and Berit L. Heitmann ${ }^{1,3,9}$ \\ ${ }^{1}$ Research Unit for Dietary Studies, Institute of Preventive Medicine, Bispebjerg and Frederiksberg Hospital, \\ The Capital Region, Hovedvejen Entrance 5, Nordre Fasanvej 57, DK-2000 Frederiksberg, Denmark \\ ${ }^{2}$ Centre for Research in Childhood Health, Institute of Sports Science and Clinical Biomechanics, \\ University of Southern Denmark, DK-5230 Odense M, Denmark \\ ${ }^{3}$ Centre for Intervention Research in Health Promotion and Disease Prevention (previous: Centre for Applied Research \\ in Health Promotion and Prevention), The National Institute of Public Health, University of Southern Denmark, \\ DK-1357 Copenhagen K, Denmark \\ ${ }^{4}$ The National Institute of Public Health, University of Southern Denmark, DK-1357 Copenhagen K, Denmark \\ ${ }^{5}$ Institute of Preventive Medicine, Bispebjerg and Frederiksberg Hospital, The Capital Region, DK-200O Frederiksberg, \\ Denmark \\ ${ }^{6}$ University College Zealand, Campus Slagelse, DK-4180 Sorø, Denmark \\ ${ }^{7}$ Department of Sports Medicine, Norwegian School of Sports Science, N-0806 Oslo, Norway \\ ${ }^{8}$ National Food Institute, Technical University of Denmark, DK-2860 Søborg, Denmark. \\ ${ }^{9}$ The Boden Institute of Obesity, Nutrition, Exercise E Eating Disorders, Sydney Medical School, Sydney University, Sydney, \\ Australia \\ (Submitted 6 February 2014 - Final revision received 8 November 2014 - Accepted 22 December 2014 - First published online 6 March 2015)
}

\section{Abstract}

Dietary intake among Danish children, in general, does not comply with the official recommendations. The objectives of the present study were to evaluate the 3-year effect of a multi-component school-based intervention on nutrient intake in children, and to examine whether an intervention effect depended on maternal education level. A total of 307 children (intervention group: $n$ 184; comparison group: $n$ 123) were included in the present study. All had information on dietary intake pre- and post-intervention (mean age $6 \cdot 8$ and 9.5 years for intervention and comparison groups, respectively) assessed by a $7-\mathrm{d}$ food record. Analyses were conducted based on the daily intake of macronutrients (energy percentage (E\%)), fatty acids (E\%), added sugar (E\%) and dietary fibre (g/d and g/MJ). Analyses were stratified by maternal education level into three categories. Changes in nutrient intake were observed in the intervention group, mainly among children of mothers with a short education ( $<10$ years). Here, intake of dietary fibre increased $(\beta=2 \cdot 1 \mathrm{~g} / \mathrm{d}, 95 \% \mathrm{CI} 0 \cdot 5$, $3 \cdot 6, P=0.01)$. Intake of protein tended to increase $(\beta=0.6 \mathrm{E} \%, 95 \% \mathrm{CI}-0 \cdot 01,1 \cdot 2, P=0.05)$, while intake of fat $(\beta=-1 \cdot 7 \mathrm{E} \%, 95 \% \mathrm{CI}$ $-3 \cdot 8,0 \cdot 3, P=0.09)$ and SFA $(\beta=-0.9,95 \% \mathrm{CI}-2 \cdot 0,0 \cdot 2, P=0 \cdot 10)$ tended to decrease. Also, a significant intervention effect was observed on the intake of SFA among children of mothers with a long education $(\beta=-0 \cdot 8,95 \%$ CI $-1 \cdot 5,-0 \cdot 03, P=0 \cdot 04)$. This multi-component school-based intervention resulted in changes in the dietary intake, particularly among children of mothers with a short education. As the dietary intake of this subgroup generally differs most from the recommendations, the results of the present study are particularly encouraging.

Key words: School-based intervention: Maternal education: Diet: Macronutrients

The high prevalence of overweight and obesity in childhood is unfortunate, since overweight children suffer from both shortand long-term health consequences ${ }^{(1,2)}$. Moreover, overweight in childhood and adolescence increases the risk of overweight in adulthood, which is associated with increased morbidity and risk of premature mortality ${ }^{(2)}$. In Denmark ${ }^{(3)}$, as in most Western countries $^{(4)}$, the prevalence of overweight and obesity is highest among children of parents with low socio-economic status (SES).

Abbreviations: CoSCIS, Copenhagen School Child Intervention Study; E\%, energy percentage; PE, physical education; SES, socio-economic status.

* Corresponding author: B. W. Jensen, fax +45 38163119, email britt.wang.jensen@regionh.dk 
Both physical activity and diet are believed to be important factors in the prevention of overweight and obesity among children. According to the results from the Danish National Dietary Survey, the general diet of Danish children (aged 4-14 years) does not comply with the official dietary recommendations. For the intakes of macronutrients, added sugar, dietary fibre and fatty acids, the recommendations are as follows: protein, 10-20 energy percentage (E\%); fat, 25-35 E \%; SFA, <10 E\%; MUFA, 10-15E\%; PUFA, 5-10 E\%; carbohydrates, 50-60 E\%; added sugar, $<10 \mathrm{E} \%$; dietary fibre $25-35 \mathrm{~g} / \mathrm{d}$ or $3 \mathrm{~g} / \mathrm{MJ}$ (for adults) and $>10 \mathrm{~g} / \mathrm{d}$ at school age, gradually increasing to reach the recommended level during adolescence (for children) ${ }^{(5)}$.

The diet among Danish children is generally too high in fat and added sugar, and the content of dietary fibre does not show the recommended increase during school age ${ }^{(6)}$. This is not ideal since consumption of energy-dense foods, due to a high fat and/or sugar content, may increase the risk of overweight $^{(7)}$. Studies have moreover shown that children of parents with low SES have unhealthier eating habits compared with children of parents with high SES, including a lower intake of fruit and vegetables and a higher intake of sweets, soft drinks and fast food ${ }^{(8-12)}$. This has also been reported among Danish adolescents (age $>11$ years) ${ }^{(13)}$, whereas a more recently published study including younger Danish children (aged 4-14 years) has found that the different eating habits according to SES are most pronounced among boys ${ }^{(14)}$.

Public schools are one of the suggested arenas for introducing health-promoting initiatives among children ${ }^{(15)}$, due to their potential to reach all children and adolescents independent of ethnicity and $\operatorname{SES}^{(16)}$. Therefore, the Copenhagen School Child Intervention Study (CoSCIS) was initiated in 2001. It was based on the initiative of the municipality of Ballerup that intended to promote health and well-being among the local school children. The intervention focused on improving both dietary intake and physical activity among the children.

The aims of the present study were to examine the effect of intervention on the dietary intake and, more specifically to examine (1) the effect of CoSCIS on the dietary intake among children (macronutrients, fatty acids, added sugar and dietary fibre) and (2) whether the effects depended on parental SES (assessed as maternal education level).

We hypothesised that the children in the intervention group would change their diet in a more healthy direction (defined as closer to the dietary recommendations) as a consequence of the intervention, and that the effect would be greater among children of mothers with a long education.

\section{Methods}

\section{Intervention}

In 1999, all public schools ( $n$ 10) in Ballerup, a suburban municipality of Copenhagen, Denmark, introduced an initiative with the focus on improving health and well-being among the local school children ${ }^{(17)}$. The intervention was multi-component (consisting of both classroom-based activities and environmental changes), and the components are briefly described below:

(1) Two additional physical education (PE) lessons per week: In all intervention schools, the two standard PE lessons per week (90 min) were increased to four PE lessons per week (180 min) throughout the school years from pre-school to third grade. In Denmark, the standard PE lessons are delivered as two weekly classes, and are mandatory for the pupils. The additional PE lessons were handled by the usual PE teachers ${ }^{(17,18)}$.

(2) Additional education of PE teachers: Each year, the PE teachers participated in a 1 -d course and six afternoon sessions ( $3 \mathrm{~h}$ ) with practical and theoretical training focusing on the development of body, healthy living and diet ${ }^{(18)}$. Also, a network was established for the PE teachers to exchange knowledge ${ }^{(19)}$, and the facilities for PE were improved ${ }^{(17,18)}$.

(3) Improvement of schoolyard environment: The schoolyard environment was improved to stimulate the children to be more physically active during recess ${ }^{(18)}$. However, the schoolyards were not all improved at day 1 of intervention, but were improved over a period of time.

(4) Parent involvement: Parents received regular information concerning a healthy diet from the municipality via newsletters from the school.

(5) Establishment of school canteens: School canteens that intended to sell healthy meals and snacks were established over time in the intervention schools with the aim of providing pupils an opportunity to buy nutritious meals in the school hours; promoting the use of school canteens by children who did not bring packed lunch from home; and improving the knowledge of children about healthy food by offering them an opportunity to be involved in running the canteen.

(6) Health education in the curriculum: Health education was incorporated into the general curriculum from the first grade to the third grade. The implementation of the intervention parts was carried out by the municipality of Ballerup, while pre- and post-measurements of diet, physical activity and anthropometrics were done by a research group. Pre- and post-measurements were also done for the comparison group.

\section{Subjects}

The ten schools in the municipality of Ballerup served as a non-randomised intervention group. All the eight public schools in Tårnby, another suburban municipality of Copenhagen, were chosen as the comparison group, as the community in Tårnby resembled the socio-demographic characteristics of Ballerup ${ }^{(20)}$. All the children entering preschool class in a public school in Ballerup or Tårnby in 2001 ( $n$ 1024) were invited to participate in the present study. Written consent for participation was given by their parents or caregivers for $69 \%$ of the children ${ }^{(17,20)}$. Information on dietary intake, anthropometrics and physical activity was collected from the children before (in the school year 2001-2 at age 6 years) and after (in the school year 2004-5 at age 9 years) the intervention period. Only children with complete information on dietary intake, both before and after the intervention, and on 
maternal education level were included in the present study. In total, 701 (intervention group: $n$ 411; comparison group: $n 290)$ children participated in the present study, of whom dietary information was obtained from 499 (49\%, intervention group: $n$ 292; comparison group: $n$ 207) children pre-intervention (Fig. 1). Of those, 139 (intervention group: $n$ 81; comparison group: $n$ 58) children were excluded from the present study, as they did not participate in the dietary assessment postintervention. An additional forty-nine (intervention group: $n 26$; comparison group: $n$ 23) children were excluded due to missing information on maternal education, and four (intervention group: $n$ 1; comparison group: $n 3$ ) children due to invalid dietary records, resulting in 307 ( $30 \%$ of the invited population) children available for the final analyses. Of those, 184 (60\%) children were from the intervention group and 123 (40\%) were from the comparison group.

\section{Ethics}

The present study was conducted according to the guidelines laid down in the Declaration of Helsinki, and all procedures involving human subjects/patients were approved by the Ethical Committee of Copenhagen County (case no. KA00011gm). Furthermore, written information about the study was given to all school leaders, teachers and parents before the start of the study.

\section{Dietary assessment}

Information on dietary intake was recorded in Spring 2002 (pre-intervention) and 2005 (post-intervention) for $7 \mathrm{~d}$ by the parents or caregivers of children in pre-printed food records. The food records were divided into four sections: breakfast; lunch; dinner and in-between snacks according to a typical

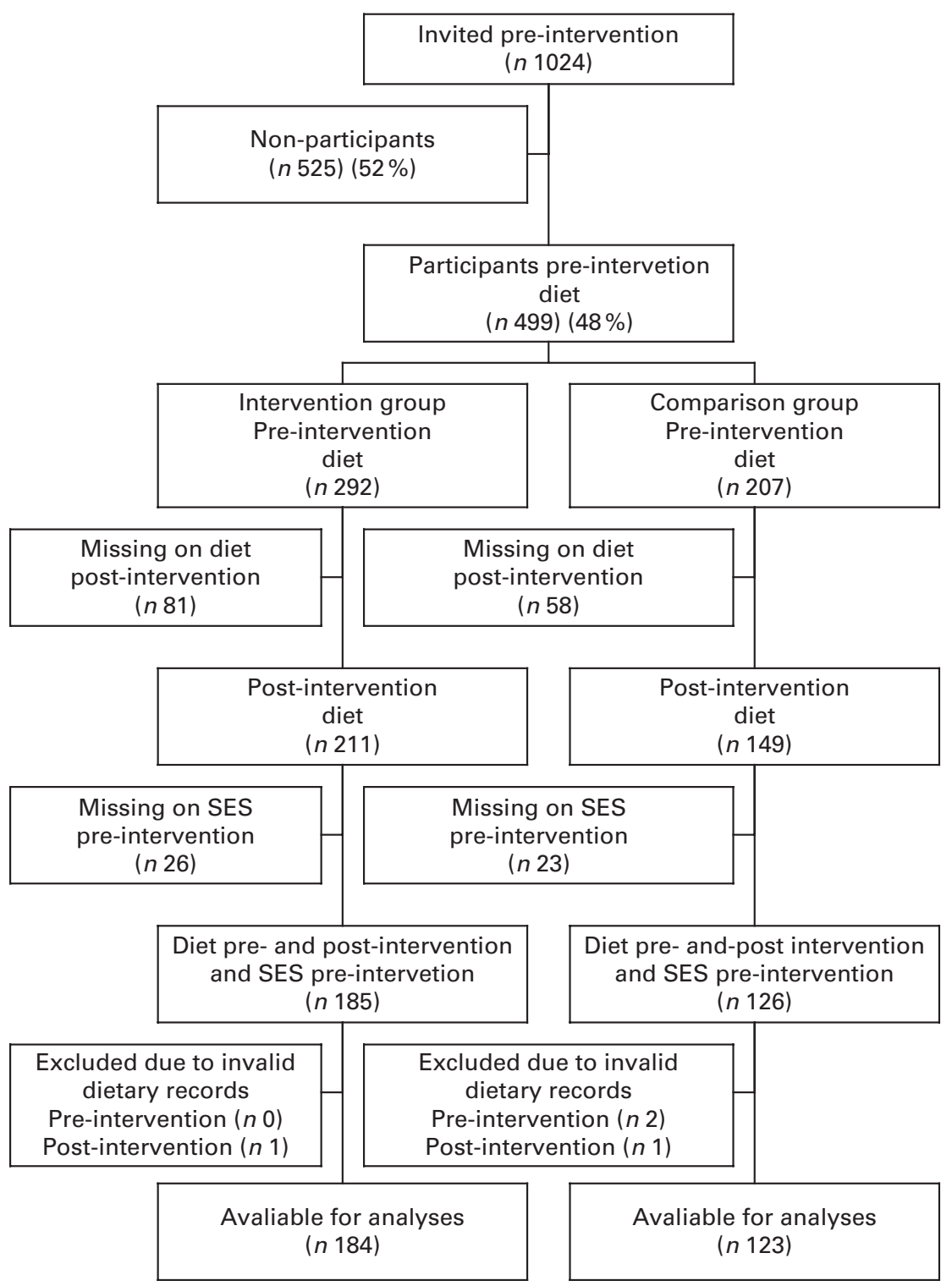

Fig. 1. Flow chart of participants included in the present study. SES, socio-economic status. 
Danish meal pattern. Each meal was further divided into several subsections with beverages, bread, cereals, vegetables, etc., and pre-printed with the most common foods and drinks, and supplemented further with an open-ended category ${ }^{(20)}$. Household measurements and a photo series illustrating common Danish foods in different portion sizes were used to estimate the amount of food eaten ${ }^{(20,21)}$. The food records were developed by the National Food Institute, Technical University of Denmark, and have been in use in the Danish nationwide dietary surveys since $1995^{(22)}$. The food records were validated in 1994 and found useful for assessing the intake of food and drink among adults ${ }^{(23)}$. Also, two studies have evaluated the pre-printed food record against an estimated energy expenditure using ActiReg measurements and a fixed physical activity level. The studies showed only modest misreporting among the children aged 7-8 years $^{(24,25)}$

The completed food records were scanned using Eyes \& Hands (version 5.2, 2005; Readsoft Ltd). Afterwards, individual intakes were calculated using the General Intake Estimation System (version 1.000, released 26 February 2010, and developed by the National Food Institute, Technical University of Denmark) and the Danish Food Composition Databank (version 6) ${ }^{(26)}$. Based on the Nordic Nutrition Recommendations ${ }^{(5)}$, the total energy intake $(\mathrm{kJ})$ was calculated as:

$$
\begin{aligned}
& \text { (carbohydrates }(\mathrm{g})-\text { dietary fibre }(\mathrm{g})) \times 17 \mathrm{~kJ} / \mathrm{g} \\
& \quad+\text { dietary fibre }(\mathrm{g}) \times 8 \mathrm{~kJ} / \mathrm{g}+\text { protein }(\mathrm{g}) \times 17 \mathrm{~kJ} / \mathrm{g} \\
& + \text { fat }(\mathrm{g}) \times 37 \mathrm{~kJ} / \mathrm{g}+\text { alcohol }(\mathrm{g}) \times 29 \mathrm{~kJ} / \mathrm{g} .
\end{aligned}
$$

The content of dietary fibre in the Danish Food Composition Databank is mainly based on the data determined using the Association of Official Analytic Chemists method and includes chemically modified starch, resistant starch, cellulose, pectins, hydrocollids, lignin, tannins/polyphenols and phytate ${ }^{(5,27)}$

Weight and height were measured by trained researchers to the nearest $0 \cdot 1 \mathrm{~kg}$ and $1 \mathrm{~mm}$, respectively, using an electronic scale (Seca 882; Medical Scales) and a transportable Harpenden stadiometer (Holtain) ${ }^{(28)}$. BMI was calculated as weight $(\mathrm{kg}) /$ height $(\mathrm{m})^{2}$, and weight status was assessed according to the cut-off points recommended by the International Obesity Task Force ${ }^{(29)}$. The reported total energy intake was evaluated according to the estimated total energy expenditure based on BMR (estimated with a predictive equation ${ }^{(30)}$ ) and physical activity. This has been described in detail elsewhere ${ }^{(31)}$. Briefly, physical activity was measured using uniaxial accelerometers (MTI 7164; Manufacturing Technology, Inc.) placed on the lower back and worn all the time for four consecutive days except during sleep and water-based activities ${ }^{(28)}$. Water-based activity was corrected afterwards for the post-intervention measure since some of the additional PE lessons provided as a part of the intervention were swimming ${ }^{(32)}$.

The dietary components included in the present study are macronutrients (protein (E\%), fat (E\%) and carbohydrates $(\mathrm{E} \%)$ ), fatty acids (SFA (E\%), MUFA (E\%), PUFA (E\%)), added sugar (E\%) and dietary fibre (g/d and $\mathrm{g} / \mathrm{MJ})$.
The intervention effect on dietary fibre was assessed both as the absolute intake $(\mathrm{g} / \mathrm{d})$ and as the relative intake $(\mathrm{g} / \mathrm{MJ})$.

The change in intake was calculated as the intake preintervention subtracted from the intake post-intervention.

\section{Additional information}

Information about maternal education was self-reported and obtained using two questions pre-intervention. The first question was 'What school education have you achieved or are you currently completing?', which could be answered using one of four fixed answers (from less than 7 years of education to completion of high school or equivalent), or an open-ended answer with the possibility to state other types of education. The second question was 'Do you have a vocational education?', with the possibility to answer 'No', or 'Yes' with seven different types of vocational education. The answers were then grouped into three categories: short - completed elementary school only ( $\leq 10$ years); medium - completed high school (12 years) or short education (3 years); long completed college or university. Maternal education level was used as a proxy for SES in the present study, as it has been associated with eating habits of the children in several studies of crosssectional $^{(33-35)}$ and longitudinal ${ }^{(8,10,36)}$ designs, and is assumed to be a useful indicator of SES in respect of this relationship.

The mothers also provided information on weight and height, which were used to calculate maternal BMI.

\section{Statistical analysis}

Descriptive characteristics of the participants pre-intervention were calculated by intervention and comparison groups, and differences between the two groups were tested using unpaired $t$ test or Wilcoxon rank-sum test for continuous variables, depending on the distribution of the data, and using $\chi^{2}$ test for categorical variables. Data were analysed using Stata version 12.0 (StataCorp LP), and $P<0.05$ was considered statistically significant.

Dietary intake is presented by intervention and comparison group and further divided by maternal education level and pre- and post-intervention. Differences in the intake between the intervention and comparison groups were tested using unpaired $t$ test or Wilcoxon rank-sum test. Differences in intakes between the three groups of maternal education levels were tested using one-way ANOVA.

Multiple regression analyses were performed to assess the effect of intervention on the dietary intake among children. Regression analyses were conducted including intervention/ comparison status of the child as the exposure and the change in each macronutrient $(\mathrm{E} \%)$, fatty acid $(\mathrm{E} \%)$, added sugar (E\%) or dietary fibre $(\mathrm{g} / \mathrm{d}$ and $\mathrm{g} / \mathrm{MJ})$ from pre- to post-intervention as the outcomes. The exposure (intervention/comparison status of the child) was included as a dichotomous variable with the comparison group as the reference group, and a dummy variable was created for the intervention group to illustrate the effect of being in the intervention group relative to being in the comparison group. 
The analyses included a crude model (adjusted for preintervention intake of a dietary component of interest and a random effect by school) and an adjusted model (adjusted for pre-intervention intake of the dietary component of interest, a random effect by school and the three-category maternal education level).

Interactions were tested for between exposure (intervention/ comparison group) and maternal education level and between exposure and sex. Also, Wald test for a non-linear association between pre-intervention intake and change in intake was conducted by adding a second-order polynomial into the model. For fat (E\%), the association between pre-intervention intake and change in intake was significantly non-linear $(P=0.01)$; thus, pre-intervention intake of fat $(\mathrm{E} \%)$ was included as a second-order polynomial in the analyses.

First, the analyses were conducted for all children adjusted for pre-intervention intake of the dietary component of interest, school and maternal education level. Analyses were repeated afterwards with stratification by maternal education level. Also, analyses stratified by maternal education level were adjusted for age and sex as sensitivity analyses to take into account possible differences between the groups. Regression analyses were repeated including all children with information on dietary intake pre-intervention and maternal education ( $n$ 415) (including children previously excluded due to missing information on dietary intake postintervention), assuming no change in dietary intake from pre- to post-intervention.

(a)

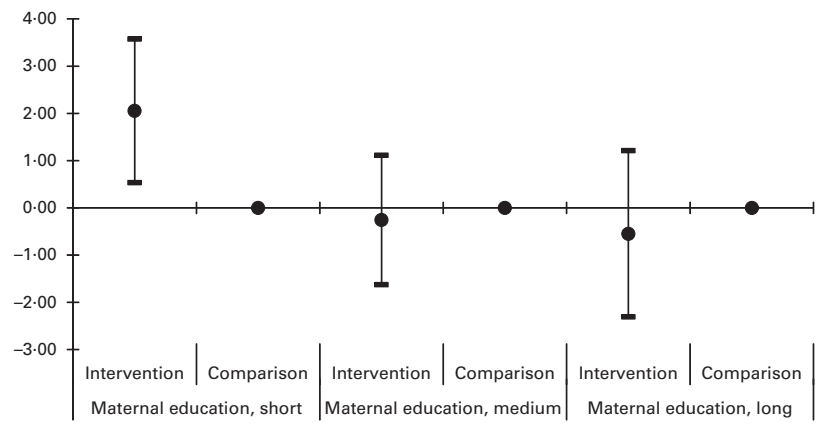

(c)

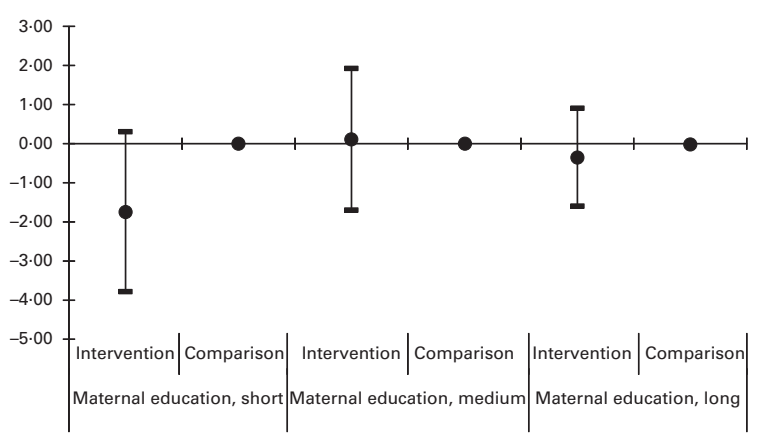

Analyses were also repeated including only children who were assessed as acceptable reporters compared with the estimated total energy expenditure both pre- and postintervention.

To visualise the changes in the intake of dietary fibre $(\mathrm{g} / \mathrm{d})$, protein $(\mathrm{E} \%)$, fat $(\mathrm{E} \%)$ and $\mathrm{SFA}(\mathrm{E} \%)$ in the intervention group relative to the comparison group, the change in the intake of each of these dietary factors from pre- to post-intervention in the intervention and comparison groups was calculated and illustrated in Fig. 2. In the figure, the comparison group served as the reference, with a value of zero, and a 95\% CI was applied for the change observed in the intervention group.

Power calculations were made using the PS - Power and Sample Size Calculation programme version 3.0.4 (http:// biostat.mc.vanderbilt.edu/PowerSampleSize $)^{(37,38)}$ to determine the level of difference possible to detect based on the number of participants, mean and standard deviations for the change in macronutrients (E\%), fatty acids (E\%), added sugar $(\mathrm{E} \%)$ and dietary fibre intake $(\mathrm{g} / \mathrm{d}, \mathrm{g} / \mathrm{MJ})$, assuming a power of $80 \%$ and a significance level of $5 \%$.

Based on the results of the power calculations, differences in change in dietary intake from pre- to post-intervention between the intervention and comparison groups should be detectable in the crude model as small as $0.6 \mathrm{E} \%$ for protein, $1.4 \mathrm{E} \%$ for fat, $0.8 \mathrm{E} \%$ for SFA, $0.6 \mathrm{E} \%$ for MUFA, $0.33 \mathrm{E} \%$ for PUFA, $1.4 \mathrm{E} \%$ for carbohydrates, $1.5 \mathrm{E} \%$ for added sugar and $1 \cdot 4 \mathrm{~g} / \mathrm{d}$ and $0 \cdot 1 \mathrm{~g} / \mathrm{MJ}$ for dietary fibre.

(b)
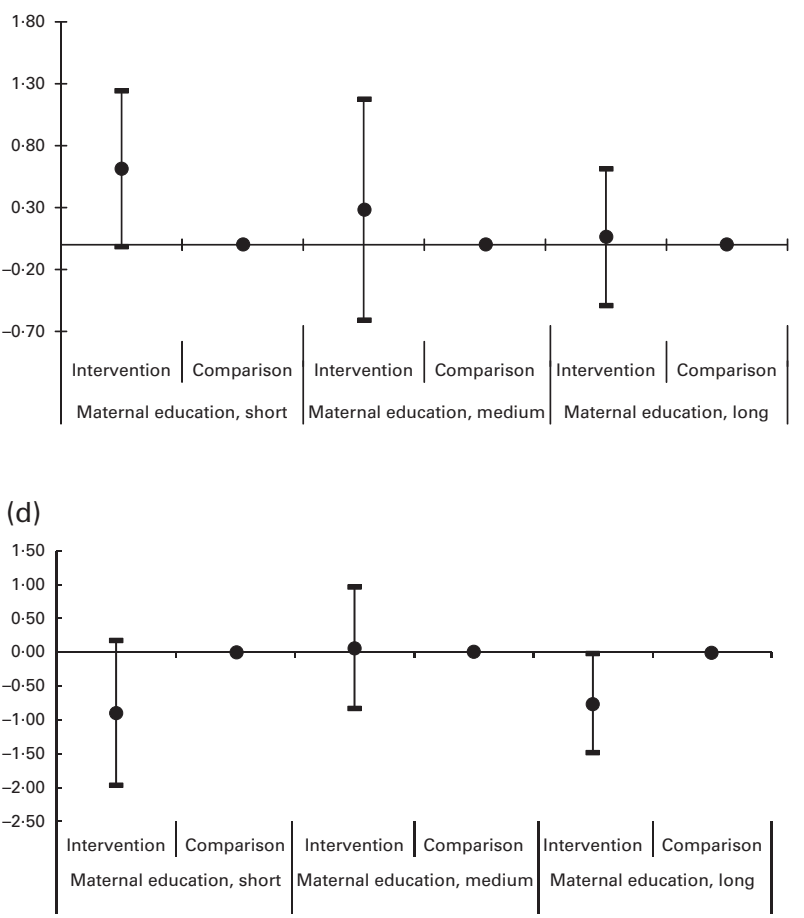

Fig. 2. Change in the intake of (a) dietary fibre ( $g / d)$, (b) protein (energy percentage, $E \%$ ), (c) fat (E\%) and (d) SFA (E\%) from pre- to post-intervention stratified by maternal education level and adjusted for pre-intervention intake of the dietary component of interest and school. The comparison group was chosen as the reference group, and $95 \% \mathrm{Cl}$ is presented for the intervention group. The figures thus show the differences in the change of dietary intake between the intervention and comparison groups in strata of maternal education level. For example, from pre- to post-intervention, the intake of dietary fibre changed $2 \mathrm{~g} / \mathrm{d}$ ( $0.5-3 \cdot 6)$ more in the intervention group than in the comparison group for children of mothers with a short education. 


\section{Results}

\section{Subjects}

Descriptive characteristics of the participants are presented separately for the intervention and comparison groups in Table 1. No variable other than age and maternal education level differed between the two groups pre-intervention.

When comparing children included and not included in the analyses (due to missing information on one or more variables or lost to follow-up), there was a tendency towards that the children not included in the analyses had a higher BMI $(P=0 \cdot 10)$. Also, the mothers of the children not included in the analyses had a shorter education $(P=0.09)$ and a higher BMI $(P=0.01)$ than the mothers of children included in the analyses. No differences were observed in sex, weight, height, age, comparison/intervention status or physical activity. The only observed dietary difference was a trend towards a higher intake of PUFA among the children included in the analyses compared with those not included (data not shown).

Before intervention, $8.7 \%$ of the children of mothers with a long education were overweight or obese. This was not significantly different from the prevalence among the children of mothers with a shorter education $(P=0.34)$. After intervention, the prevalence of overweight/obese children tended to be lower among the children of mothers with a long education

Table 1. Pre-intervention characteristics of the participants of intervention/comparison group

(Mean values and standard deviations; number of participants and percentages)

\begin{tabular}{|c|c|c|c|c|c|}
\hline & \multicolumn{2}{|c|}{$\begin{array}{l}\text { Intervention } \\
\text { group } \\
(n 184)\end{array}$} & \multicolumn{2}{|c|}{$\begin{array}{c}\text { Comparison } \\
\text { group } \\
(n 123)\end{array}$} & \multirow[b]{2}{*}{$P$} \\
\hline & Mean & SD & Mean & SD & \\
\hline \multicolumn{5}{|l|}{ Boys* } & 0.11 \\
\hline$n$ & \multicolumn{2}{|c|}{95} & \multicolumn{2}{|c|}{52} & \\
\hline$\%$ & \multicolumn{2}{|c|}{52} & \multicolumn{2}{|c|}{42} & \\
\hline Age (years)†‡ & $6 \cdot 8$ & 0.3 & $6 \cdot 7$ & 0.3 & 0.01 \\
\hline Weight $(\mathrm{kg})+\S$ & $24 \cdot 1$ & 3.0 & $24 \cdot 0$ & 3.6 & 0.73 \\
\hline Height $(\mathrm{cm}) \dagger \S$ & 123.4 & 4.8 & $122 \cdot 7$ & 4.7 & 0.19 \\
\hline BMI $\left(\mathrm{kg} / \mathrm{m}^{2}\right)+\S$ & $15 \cdot 8$ & 1.4 & $15 \cdot 9$ & 1.6 & 0.64 \\
\hline Physical activity $(\mathrm{cpm}) \| \boldsymbol{q}$ & 733 & 208 & 745 & 201 & 0.65 \\
\hline Maternal BMI $\left(\mathrm{kg} / \mathrm{m}^{2}\right) \dagger^{\star \star}$ & $23 \cdot 3$ & 3.9 & $23 \cdot 6$ & 4.3 & 0.58 \\
\hline \multicolumn{5}{|l|}{ Maternal education, short ${ }^{\star}$} & 0.01 \\
\hline$n$ & \multicolumn{2}{|c|}{46} & \multicolumn{2}{|c|}{43} & \\
\hline$\%$ & \multicolumn{2}{|c|}{25} & \multicolumn{2}{|c|}{35} & \\
\hline \multicolumn{6}{|l|}{ Maternal education, medium ${ }^{*}$} \\
\hline$n$ & \multicolumn{2}{|c|}{64} & \multicolumn{2}{|c|}{50} & \\
\hline$\%$ & \multicolumn{2}{|c|}{35} & \multicolumn{2}{|c|}{41} & \\
\hline \multicolumn{6}{|l|}{ Maternal education, long ${ }^{*}$} \\
\hline$n$ & \multicolumn{2}{|c|}{74} & \multicolumn{2}{|c|}{30} & \\
\hline$\%$ & \multicolumn{2}{|c|}{40} & \multicolumn{3}{|c|}{25} \\
\hline
\end{tabular}

cpm, counts per min

* Differences between intervention and comparison groups tested by $\chi^{2}$ test.

†Differences between intervention and comparison groups tested by unpaired $t$ test.

† Comparison group ( $n$ 122)

$\S$ Comparison group ( $n$ 121).

|| Differences between intervention and comparison groups tested by Wilcoxon rank-sum test.

II Intervention group ( $n$ 160) and comparison group ( $n$ 102).

** Intervention group ( $n$ 176) and comparison group ( $n$ 118)
(6.8\%) than that among the children of mothers with a medium education $(17.5 \%)$ or a short education $(15.9 \%$, $P=0 \cdot 05$; data not shown)

\section{Mean dietary intake pre-intervention}

Before intervention, a significantly larger proportion of the total energy intake in the comparison group was derived from fat $(\mathrm{E} \%)$ compared with the intervention group $(P=0.03)$. Especially, a higher intake of MUFA (E\%) was observed in the comparison group relative to the intervention group $(P=0 \cdot 01)$. However, a trend towards a higher intake of PUFA (E\%) $(P=0.08)$ was also observed, whereas no difference was observed for the intake of SFA (E\%) $(P=0.46)$ (Table 2). In addition, there was a trend towards a larger proportion of the total energy intake from protein $(\mathrm{E} \%)(P=0 \cdot 10)$ among children of the intervention group.

Stratified by maternal education level, no significant mean differences were observed between the comparison group and the intervention group in dietary intake pre-intervention. A trend towards a higher intake of protein $(\mathrm{E} \%)(P=0.06)$ and a lower intake of MUFA (E\%) $(P=0.09)$ was observed among the children of mothers with a long education in the intervention group compared with the comparison group. Also, a trend towards a higher intake of SFA (E\%) was observed in the intervention group among the children of mothers with a short education $(P=0 \cdot 10)$ (Table 3$)$. Overall, the pre-intervention diet of the participants did not correspond to the Nordic Nutritional Recommendations ${ }^{(5)}$, as in both the intervention and the comparison groups, the mean proportion of energy derived from fat, SFA and added sugar was higher, and the intake of carbohydrates was lower than recommended. However, the intake of dietary fibre fulfilled the Nordic Nutritional Recommendations for that age group.

\section{Evaluation of dietary intake}

Out of 217 children with information on diet and physical activity both pre- and post-intervention, 167 children were assessed as acceptable reporters according to the estimated energy expenditure both pre- and post-intervention, and forty-eight children were assessed as under-reporters pre- or post-intervention (pre-intervention: $n$ 11; post-intervention $n$ 42). Two children were assessed as over-reporters preintervention, while none of the children was assessed as over-reporters post-intervention. Reporting status was not significantly different between intervention and comparison groups pre- or post-intervention $(P>0.57)$. Significant differences in reporting status were observed with maternal education level (pre-intervention: $P=0.01$; post-intervention: $P=0.004)$, where fewer children of mothers with a long education were assessed as misreporters.

\section{Intervention effects on dietary intake}

The dietary intake post-intervention was generally healthier among children from the intervention group compared with those from the comparison group (Table 2). Regression 
Table 2. Dietary intake pre- and post-intervention by intervention/comparison group

(Mean values and standard deviations)

\begin{tabular}{|c|c|c|c|c|c|c|}
\hline & \multirow[b]{2}{*}{ Time } & \multicolumn{2}{|c|}{$\begin{array}{l}\text { Intervention } \\
(n 184)\end{array}$} & \multicolumn{2}{|c|}{$\begin{array}{l}\text { Comparison } \\
(n 123)\end{array}$} & \multirow[b]{2}{*}{$P$} \\
\hline & & Mean & SD & Mean & SD & \\
\hline \multirow[t]{2}{*}{ Energy $(\mathrm{MJ})^{*}$} & Pre-intervention & $8 \cdot 4$ & 1.6 & $8 \cdot 3$ & $1 \cdot 7$ & 0.47 \\
\hline & Post-intervention & $8 \cdot 3$ & $1 \cdot 7$ & $8 \cdot 2$ & $1 \cdot 7$ & 0.36 \\
\hline \multirow[t]{2}{*}{ Total fat $(\mathrm{E} \%)^{*}$} & Pre-intervention & $35 \cdot 4$ & 4.4 & 36.5 & $4 \cdot 3$ & 0.03 \\
\hline & Post-intervention & 34.5 & 4.6 & $35 \cdot 5$ & 4.5 & 0.06 \\
\hline \multirow[t]{2}{*}{ SFA $(E \%)^{*}$} & Pre-intervention & $16 \cdot 2$ & $2 \cdot 4$ & $16 \cdot 4$ & $2 \cdot 5$ & 0.46 \\
\hline & Post-intervention & $15 \cdot 4$ & 2.5 & $15 \cdot 9$ & $2 \cdot 2$ & 0.07 \\
\hline \multirow[t]{2}{*}{ MUFA $(E \%)^{*}$} & Pre-intervention & $12 \cdot 1$ & 1.8 & $12 \cdot 6$ & 1.7 & 0.01 \\
\hline & Post-intervention & $11 \cdot 6$ & $1 \cdot 7$ & $12 \cdot 0$ & $1 \cdot 8$ & 0.07 \\
\hline \multirow[t]{2}{*}{ PUFA (E\%)† } & Pre-intervention & $5 \cdot 0$ & $1 \cdot 0$ & $5 \cdot 2$ & $1 \cdot 1$ & 0.08 \\
\hline & Post-intervention & 4.7 & 0.9 & 4.8 & $1 \cdot 1$ & 0.87 \\
\hline \multirow[t]{2}{*}{ Protein $(\mathrm{E} \%)^{*}$} & Pre-intervention & $14 \cdot 0$ & $1 \cdot 8$ & $13 \cdot 7$ & $1 \cdot 8$ & $0 \cdot 10$ \\
\hline & Post-intervention & 14.6 & $2 \cdot 1$ & 14.0 & 1.9 & 0.03 \\
\hline \multirow[t]{2}{*}{ Carbohydrate $(\mathrm{E} \%)^{*}$} & Pre-intervention & $49 \cdot 0$ & $4 \cdot 3$ & $48 \cdot 3$ & $4 \cdot 3$ & 0.14 \\
\hline & Post-intervention & $49 \cdot 3$ & $4 \cdot 2$ & 48.9 & 4.5 & 0.40 \\
\hline \multirow[t]{2}{*}{ Added sugar (E\%)† } & Pre-intervention & $12 \cdot 6$ & $4 \cdot 6$ & $13 \cdot 2$ & $4 \cdot 6$ & 0.25 \\
\hline & Post-intervention & $11 \cdot 3$ & $4 \cdot 3$ & $12 \cdot 2$ & $4 \cdot 7$ & 0.11 \\
\hline \multirow[t]{2}{*}{ Dietary fibre $(g / d) \dagger$} & Pre-intervention & $16 \cdot 9$ & 4.4 & $15 \cdot 9$ & 3.7 & $0 \cdot 11$ \\
\hline & Post-intervention & $17 \cdot 2$ & 4.5 & $16 \cdot 2$ & $4 \cdot 3$ & 0.01 \\
\hline \multirow[t]{2}{*}{ Dietary fibre $(\mathrm{g} / \mathrm{MJ}) \dagger$} & Pre-intervention & $2 \cdot 0$ & 0.4 & $2 \cdot 0$ & 0.4 & 0.26 \\
\hline & Post-intervention & $2 \cdot 1$ & 0.4 & $2 \cdot 0$ & 0.4 & 0.19 \\
\hline
\end{tabular}

$\mathrm{E} \%$, energy percentage.

* Differences between intervention and comparison groups were tested by unpaired $t$ test.

†Differences between intervention and comparison groups were tested by Wilcoxon rank-sum test.

analyses did not show significant associations between intervention/comparison status of the child and change in dietary intake from pre- to post-intervention (both crude and adjusted models). A trend towards lower intake of fat $(\mathrm{E} \%)(P=0 \cdot 10)$ and SFA (E\%) $(P=0.09)$ was observed in the adjusted models (Table 4).

\section{Intervention effects on dietary intake according to maternal education level}

In the regression analyses stratified by maternal education level and adjusted for pre-intervention intake of the dietary component of interest and school, it was observed that the absolute intake of dietary fibre $(\mathrm{g} / \mathrm{d})$ increased $(P=0.01)$ among the children of mothers with a short education during the intervention period relative to the same group of children from the comparison group (Table 5). A similar trend was observed for the analysis of dietary fibre relative to the total energy intake $(\mathrm{g} / \mathrm{MJ})$, although it was non-significant $(P=0 \cdot 28)$. Also, there was a trend towards an increased intake of protein $(\mathrm{E} \%)(P=0.05)$ and decreased intakes of fat $(\mathrm{E} \%)(P=0.09)$ and SFA (E\%) $(P=0 \cdot 10)$ among children of mothers with a short education during the intervention period, but these changes were of borderline significance (Fig. 2). Thus, among children in the intervention group of mothers with a short education, the intake of dietary fibre increased ( $P=0.01$ ) from 15.9 (SD 4.2 ) to 16.7 (SD 4.9$) \mathrm{g} / \mathrm{d}$, and the intake of protein showed a trend towards an increase from $14 \cdot 1$ (SD 2.0) to 14.8 ( $\mathrm{SD} 2 \cdot 2$ ) $\mathrm{E} \%$, while the intake of fat tended to decrease from 36.3 (SD 4.3) to 33.9 (SD 4.8 ) $\mathrm{E} \%$, and the intake of SFA tended to decrease from $16 \cdot 7$ (SD 2.3) to 15.4 (SD 2.9) $\mathrm{E} \%$. Also, among the children of mothers with a long education, a significant decrease in the intake of SFA was observed from 16.1 (SD 2.5) to 15.4 (SD 2.6) E\% $(P=0.04)$ (Tables 3 and 5, Fig. 2).

\section{Sensitivity analyses}

Sensitivity analyses adjusted for age and sex showed overall similar trends in the results (data not shown).

Sensitivity analyses were also conducted including children with missing information on dietary intake postintervention, with an assumption of a stable intake from preto post-intervention. In these analyses, the same trends were observed as those observed in the analyses including children with information on both dietary collections; however, the association was significant for the intake of dietary fibre $(\mathrm{g} / \mathrm{d})$ among the children of mothers with a short education ( $\beta=1.57,95 \%$ CI $0.52,2.62, P=0.006$; data not shown).

When the analyses were repeated, including only the children assessed as acceptable reporters, the increased intake of dietary fibre $(\mathrm{g} / \mathrm{d})$ among children of mothers with a short education was of borderline significance $(\beta=2 \cdot 21$, $95 \%$ CI $\left.-0.33,4 \cdot 75, P=0 \cdot 08, R^{2} 0 \cdot 26\right)$, while a trend towards a decreased intake of dietary fibre $(\mathrm{g} / \mathrm{d})$ was observed among the children of mothers with a long education $(\beta=-1.42$, $95 \%$ CI $-3.03,0 \cdot 20, P=0.08, R^{2} 0 \cdot 30$ ) (data not shown). The lower intake of dietary fibre remained significant among children of mothers with a long education when the intake of dietary fibre was assessed according to total energy intake $(\mathrm{g} / \mathrm{MJ})\left(\beta=-0 \cdot 17,95 \% \mathrm{CI}-0 \cdot 30,-0 \cdot 03, P=0 \cdot 02, R^{2} 0 \cdot 22\right)$. 
Table 3. Pre-intervention dietary intake of intervention/comparison group by maternal education level

(Mean values and standard deviations)

\begin{tabular}{|c|c|c|c|c|c|c|c|c|c|c|c|}
\hline & \multirow[b]{3}{*}{ Maternal education } & & \multicolumn{3}{|c|}{ Pre-intervention } & \multirow[b]{3}{*}{$P$} & \multicolumn{4}{|c|}{ Post-intervention } & \multirow[b]{3}{*}{$P$} \\
\hline & & \multicolumn{2}{|c|}{ Intervention } & \multicolumn{2}{|c|}{ Comparison } & & \multicolumn{2}{|c|}{ Intervention } & \multicolumn{2}{|c|}{ Comparison } & \\
\hline & & Mean & SD & Mean & $\mathrm{SD}$ & & Mean & SD & Mean & $\mathrm{SD}$ & \\
\hline \multirow[t]{3}{*}{ Energy $(\mathrm{MJ})^{*}$} & Short & 8.4 & 1.7 & $8 \cdot 2$ & 1.5 & 0.53 & $8 \cdot 4$ & $2 \cdot 3$ & $7 \cdot 8$ & $2 \cdot 0$ & 0.18 \\
\hline & Medium & 8.5 & 1.7 & $8 \cdot 1$ & 1.9 & 0.31 & $8 \cdot 1$ & 1.5 & 8.2 & $1 \cdot 8$ & 0.83 \\
\hline & Long & $8 \cdot 3$ & 1.5 & 8.6 & 1.5 & 0.42 & 8.5 & 1.4 & $8 \cdot 7$ & 1.3 & 0.61 \\
\hline \multirow[t]{3}{*}{ Protein $(E \%)^{\star}$} & Short & $14 \cdot 1$ & $2 \cdot 0$ & $13 \cdot 8$ & 1.9 & 0.43 & $14 \cdot 8$ & $2 \cdot 2$ & $14 \cdot 0$ & $2 \cdot 0$ & 0.09 \\
\hline & Medium & $13 \cdot 8$ & 1.8 & $13 \cdot 7$ & 1.9 & 0.71 & $14 \cdot 3$ & $2 \cdot 1$ & $14 \cdot 0$ & $2 \cdot 0$ & 0.41 \\
\hline & Long & $14 \cdot 1$ & $1 \cdot 8$ & $13 \cdot 4$ & 1.3 & 0.06 & 14.7 & $2 \cdot 0$ & $14 \cdot 2$ & 1.9 & 0.27 \\
\hline \multirow[t]{3}{*}{ Fat $(E \%)^{*}$} & Short & $36 \cdot 3$ & $4 \cdot 3$ & $36 \cdot 6$ & $4 \cdot 1$ & 0.74 & 33.9 & $4 \cdot 8$ & 35.8 & $5 \cdot 0$ & 0.07 \\
\hline & Medium & $35 \cdot 0$ & 4.5 & $36 \cdot 4$ & 4.7 & 0.11 & 34.5 & $4 \cdot 1$ & 34.9 & 4.4 & 0.66 \\
\hline & Long & $35 \cdot 2$ & 4.5 & $36 \cdot 7$ & $4 \cdot 1$ & $0 \cdot 11$ & 34.8 & 4.9 & $36 \cdot 0$ & 3.7 & 0.23 \\
\hline \multirow[t]{3}{*}{ SFA $(E \%)^{*}$} & Short & $16 \cdot 7$ & $2 \cdot 3$ & $16 \cdot 0$ & $2 \cdot 1$ & $0 \cdot 10$ & $15 \cdot 4$ & $2 \cdot 9$ & $16 \cdot 0$ & $2 \cdot 3$ & 0.28 \\
\hline & Medium & $16 \cdot 1$ & $2 \cdot 3$ & $16 \cdot 7$ & $2 \cdot 8$ & $0 \cdot 16$ & $15 \cdot 4$ & $2 \cdot 2$ & $15 \cdot 6$ & $2 \cdot 3$ & 0.72 \\
\hline & Long & $16 \cdot 1$ & 2.5 & $16 \cdot 6$ & $2 \cdot 2$ & 0.30 & $15 \cdot 4$ & $2 \cdot 6$ & $16 \cdot 4$ & 1.9 & 0.06 \\
\hline \multirow{3}{*}{ MUFA (E\%)* } & Short & $12 \cdot 4$ & 1.6 & $12 \cdot 7$ & 1.9 & 0.33 & 11.4 & $1 \cdot 7$ & $12 \cdot 1$ & 1.9 & 0.06 \\
\hline & Medium & $11 \cdot 9$ & $1 \cdot 8$ & $12 \cdot 4$ & $1 \cdot 7$ & $0 \cdot 15$ & 11.6 & $1 \cdot 6$ & $11 \cdot 8$ & 1.7 & 0.57 \\
\hline & Long & $12 \cdot 0$ & 1.8 & $12 \cdot 6$ & 1.6 & 0.09 & $11 \cdot 7$ & 1.9 & $12 \cdot 0$ & 1.7 & 0.44 \\
\hline \multirow[t]{3}{*}{ PUFA (E\%)† } & Short & $5 \cdot 0$ & 0.9 & $5 \cdot 4$ & $1 \cdot 2$ & 0.22 & $4 \cdot 6$ & $1 \cdot 0$ & 4.9 & $1 \cdot 1$ & 0.08 \\
\hline & Medium & $5 \cdot 0$ & $1 \cdot 1$ & 5.0 & 1.0 & 0.74 & $4 \cdot 8$ & 0.9 & $4 \cdot 8$ & 1.3 & 0.64 \\
\hline & Long & $5 \cdot 0$ & 0.9 & $5 \cdot 2$ & $1 \cdot 1$ & 0.34 & 4.8 & 1.0 & $4 \cdot 6$ & 1.0 & 0.34 \\
\hline \multirow[t]{3}{*}{ Carbohydrate $(\mathrm{E} \%)^{*}$} & Short & $48 \cdot 1$ & $4 \cdot 2$ & $48 \cdot 1$ & $4 \cdot 3$ & 0.99 & $49 \cdot 7$ & $4 \cdot 2$ & $48 \cdot 6$ & 4.9 & 0.28 \\
\hline & Medium & $49 \cdot 6$ & 4.4 & $48 \cdot 4$ & 4.5 & 0.15 & 49.5 & 3.9 & 49.5 & 4.5 & 0.98 \\
\hline & Long & $49 \cdot 0$ & $4 \cdot 1$ & $48 \cdot 3$ & $4 \cdot 0$ & 0.39 & $48 \cdot 8$ & 4.4 & $48 \cdot 1$ & 3.8 & 0.44 \\
\hline \multirow[t]{3}{*}{ Added sugar $(\mathrm{E} \%) \dagger$} & Short & $12 \cdot 8$ & 5.0 & 13.5 & 5.0 & 0.49 & 11.6 & 4.4 & $12 \cdot 4$ & 4.9 & 0.74 \\
\hline & Medium & $13 \cdot 4$ & 4.6 & $13 \cdot 1$ & $4 \cdot 8$ & 0.56 & $12 \cdot 0$ & $5 \cdot 0$ & $12 \cdot 4$ & $4 \cdot 6$ & 0.48 \\
\hline & Long & $11 \cdot 7$ & $4 \cdot 3$ & $13 \cdot 1$ & 3.7 & $0 \cdot 11$ & 10.5 & $3 \cdot 3$ & $11 \cdot 4$ & $4 \cdot 8$ & 0.23 \\
\hline \multirow[t]{3}{*}{ Dietary fibre $(\mathrm{g} / \mathrm{d}) \dagger$} & Short & $15 \cdot 9$ & 4.2 & $15 \cdot 5$ & 3.1 & 0.69 & $16 \cdot 7$ & 4.9 & $14.4 \ddagger$ & 3.1 & 0.03 \\
\hline & Medium & $16 \cdot 8$ & $4 \cdot 1$ & $15 \cdot 8$ & $4 \cdot 1$ & 0.22 & $16 \cdot 8$ & $4 \cdot 4$ & $16 \cdot 5 \ddagger$ & 4.4 & 0.31 \\
\hline & Long & 17.5 & 4.7 & $16 \cdot 8$ & 3.6 & 0.73 & $18 \cdot 0$ & 4.2 & $18 \cdot 2 \ddagger$ & 4.7 & 0.93 \\
\hline \multirow[t]{3}{*}{ Dietary fibre $(\mathrm{g} / \mathrm{MJ}) \dagger$} & Short & $1.9 \ddagger$ & 0.3 & 1.9 & 0.4 & 0.69 & $2 \cdot 0$ & 0.4 & 1.9 & 0.4 & 0.23 \\
\hline & Medium & $2.0 \ddagger$ & 0.4 & $2 \cdot 0$ & 0.4 & 0.58 & $2 \cdot 1$ & 0.4 & $2 \cdot 0$ & 0.4 & 0.70 \\
\hline & Long & $2 \cdot 1 \ddagger$ & 0.5 & $2 \cdot 0$ & 0.4 & 0.29 & $2 \cdot 1$ & 0.4 & $2 \cdot 1$ & 0.5 & 0.95 \\
\hline
\end{tabular}

E\%, energy percentage.

* Differences between intervention and comparison groups were tested by unpaired $t$ test.

†Differences between intervention and comparison groups were tested by Wilcoxon rank-sum test.

$\ddagger$ Mean value was significantly different for dietary intake by maternal education levels (dietary fibre (g/MJ): $P=0.009$, dietary fibre $(\mathrm{g} / \mathrm{d})$ : $P=0.0006$; ANOVA).

In the analyses including all children, we observed a significant decrease in the intake of SFA (E\%) among the children of mothers with a long education, which remained significant when only the acceptable reporters were included
( $\left.\beta=-0.88,95 \% \mathrm{CI}-1.69,-0 \cdot 07, P=0 \cdot 04, R^{2} 0 \cdot 41\right)$. However, the trend towards decreased intake of SFA (E\%) observed among children of mothers with a short education was not evident among the children assessed as acceptable reports

Table 4. Association between intervention/comparison status and change in nutrient intake from pre- to post-intervention* ( $\beta$-Coefficients and $95 \%$ confidence intervals)

\begin{tabular}{|c|c|c|c|c|c|c|c|c|}
\hline & \multicolumn{4}{|c|}{ Crude model } & \multicolumn{4}{|c|}{ Adjusted } \\
\hline & $\beta$ & $95 \% \mathrm{Cl}$ & $P$ & $R^{2}$ & $\beta$ & $95 \% \mathrm{Cl}$ & $P$ & $R^{2}$ \\
\hline$\Delta$ Protein (E\%) & 0.37 & $-0.09,0.83$ & 0.11 & $0 \cdot 21$ & 0.34 & $-0.11,0.79$ & 0.13 & 0.22 \\
\hline$\Delta$ Fat $(\mathrm{E} \%) \dagger$ & -0.53 & $-1 \cdot 23,0.16$ & 0.12 & 0.29 & -0.63 & $-1.40,0.13$ & 0.10 & 0.29 \\
\hline$\Delta \mathrm{SFA}(\mathrm{E} \%)$ & -0.43 & $-0.95,0.08$ & 0.10 & 0.33 & -0.47 & $-1.02,0.08$ & 0.09 & 0.33 \\
\hline$\Delta$ MUFA (E\%) & -0.17 & $-0.47,0.12$ & 0.24 & 0.31 & $-0 \cdot 20$ & $-0.53,0.13$ & 0.22 & 0.32 \\
\hline$\Delta$ PUFA (E\%) & 0.04 & $-0.20,0.27$ & 0.75 & 0.29 & 0.03 & $-0.21,0.27$ & 0.80 & 0.29 \\
\hline$\Delta$ Carbohydrates (E\%) & 0.14 & $-0.59,0.86$ & 0.69 & 0.31 & 0.27 & $-0.48,1.02$ & 0.45 & 0.31 \\
\hline$\Delta$ Added sugar $(\mathrm{E} \%)$ & -0.56 & $-1 \cdot 60,0.48$ & 0.27 & 0.28 & -0.45 & $-1.47,0.58$ & 0.37 & 0.29 \\
\hline$\Delta$ Dietary fibre $(\mathrm{g} / \mathrm{d})^{\prime}$ & 0.57 & $-0.31,1.45$ & 0.19 & 0.20 & 0.39 & $-0.46,1.23$ & 0.35 & 0.22 \\
\hline$\Delta$ Dietary fibre (g/MJ) & 0.03 & $-0.07,0.14$ & 0.50 & 0.22 & 0.03 & $-0.08,0.14$ & 0.61 & 0.22 \\
\hline
\end{tabular}

$\Delta$, change in dietary intake from pre- to post-intervention; E\%, energy percentage.

* Variables were analysed by multiple regression analyses with intervention/comparison status as dichotomous exposure (with the comparison group as reference) and adjusted for pre-intervention intake of the dietary component of interest and school in the crude analyses and additionally for maternal education level in the adjusted analyses.

$\dagger$ Regression analysis included a second-order polynomial for pre-intervention intake of fat $(\mathrm{E} \%)$. 
Table 5. Association between intervention/comparison status and change in dietary intake from pre- to post-intervention stratified by maternal education level ${ }^{*}$

( $\beta$-Coefficients and $95 \%$ confidence intervals)

\begin{tabular}{|c|c|c|c|c|c|c|c|c|c|c|c|c|}
\hline & \multicolumn{12}{|c|}{ Maternal education level } \\
\hline & \multicolumn{4}{|c|}{ Short $(n 89)$} & \multicolumn{4}{|c|}{ Medium ( $n$ 114) } & \multicolumn{4}{|c|}{ Long (n 104) } \\
\hline & $\beta$ & $95 \% \mathrm{Cl}$ & $P$ & $R^{2}$ & $\beta$ & $95 \% \mathrm{Cl}$ & $P$ & $R^{2}$ & $\beta$ & $95 \% \mathrm{Cl}$ & $P$ & $R^{2}$ \\
\hline$\Delta$ Protein $(\mathrm{E} \%)$ & 0.61 & $-0.01,1.24$ & 0.05 & 0.24 & 0.28 & $-0.61,1.17$ & 0.51 & 0.27 & 0.06 & $-0.49,0.61$ & 0.82 & 0.13 \\
\hline$\Delta$ Fat $(\mathrm{E} \%) \dagger$ & -1.74 & $-3.78,0.29$ & 0.09 & 0.25 & $0 \cdot 11$ & $-1.70,1.92$ & 0.90 & 0.38 & -0.35 & $-1.61,0.91$ & 0.56 & 0.27 \\
\hline$\Delta$ SFA (E\%) & -0.90 & $-1.97,0.17$ & $0 \cdot 10$ & 0.27 & 0.07 & $-0.82,0.96$ & 0.87 & 0.41 & -0.76 & $-1.49,-0.03$ & 0.04 & 0.31 \\
\hline$\Delta$ MUFA (E\%) & -0.60 & $-1.44,0.25$ & 0.15 & 0.31 & -0.02 & $-0.75,0.71$ & 0.96 & 0.36 & -0.02 & $-0.58,0.55$ & 0.95 & 0.27 \\
\hline$\Delta$ PUFA (E\%) & -0.16 & $-0.57,0.24$ & 0.41 & 0.31 & 0.01 & $-0.30,0.31$ & 0.97 & 0.31 & 0.26 & $-0.12,0.65$ & 0.17 & 0.26 \\
\hline$\Delta$ Carbohydrate $(\mathrm{E} \%)$ & 1.05 & $-0.67,2.77$ & 0.22 & 0.30 & -0.39 & $-1.80,1.03$ & 0.57 & 0.38 & 0.33 & $-0.93,1.59$ & 0.59 & 0.23 \\
\hline$\Delta$ Added sugar (E\%) & -0.44 & $-1.60,0.71$ & 0.43 & 0.30 & -0.56 & $-2 \cdot 42,1 \cdot 29$ & 0.53 & 0.27 & -0.26 & $-1.63,1.12$ & 0.70 & 0.30 \\
\hline$\Delta$ Dietary fibre $(\mathrm{g} / \mathrm{d})$ & 2.05 & $0.53,3.58$ & 0.01 & 0.24 & -0.25 & $-1.63,1.12$ & $0 \cdot 70$ & $0 \cdot 18$ & -0.55 & $-2 \cdot 31,1 \cdot 21$ & 0.52 & 0.28 \\
\hline$\Delta$ Dietary fibre $(\mathrm{g} / \mathrm{MJ})$ & 0.11 & $-0.09,0.31$ & 0.28 & 0.24 & 0.02 & $-0.14,0.17$ & 0.81 & 0.27 & -0.06 & $-0.23,0.10$ & 0.41 & 0.19 \\
\hline
\end{tabular}

$\Delta$, change in dietary intake from pre- to post-intervention; $\mathrm{E} \%$, energy percentage.

* Variables were analysed by multiple regression analyses with intervention/comparison status as dichotomous exposure (with the comparison group as reference), stratified by maternal education level and adjusted for pre-intervention intake of the dietary component of interest and school.

$\dagger$ Regression analysis included a second-order polynomial for the pre-intervention intake of fat $(\mathrm{E} \%)$.

$\left(\beta=-0 \cdot 66,95 \% \mathrm{CI}-2 \cdot 40,1 \cdot 07, P=0 \cdot 43, R^{2} 0 \cdot 31\right)$. Moreover, a trend towards a decreased intake of PUFA (E\%) was observed among children of mothers with a short education $\left(\beta=-0.53,95 \% \mathrm{CI}-1 \cdot 11,0 \cdot 06, P=0 \cdot 07, R^{2} 0 \cdot 43\right)$.

\section{Discussion}

In the present study, we examined the effects on the dietary intake of the school-based intervention (COSCIS), and whether these effects depended on maternal education level. After the 3-year intervention, we observed significant or borderline significant changes in the intake of dietary fibre $(\mathrm{g} / \mathrm{d})$, fat $(\mathrm{E} \%)$, SFA $(\mathrm{E} \%)$ and protein (E\%) in the intervention group compared with the comparison group among the children of mothers with a short education, while a significant decreased intake of SFA (E\%) was observed among the children of mothers with a long education.

Due to the less healthy eating habits among the children from low SES families compared with children from high SES families as reported in some studies ${ }^{(13,14)}$, especially the changes observed among the children of mothers with a short education were encouraging. It suggests that schoolbased interventions might be successful in reaching the specific low SES subgroup that is often considered a group that is difficult to reach. Moreover, it is often considered the group that is in need of utmost changes and to be at the highest risk of developing non-communicable diseases such as overweight and obesity in the future.

We were able to identify only a limited number of published multi-component school-based intervention studies assessing the intervention effects on the dietary intake of macronutrients, fatty acids, added sugar or dietary fibre in children ${ }^{(39-46)}$. Some of these studies have reported changes in the intake of fat in the intervention group during the intervention periods ${ }^{(39,40,42,44,45)}$, but not all ${ }^{(43,46)}$. In two studies, they found, similar to our finding, an increased intake of dietary fibre after the intervention period ${ }^{(40,43)}$. However, none of these studies assessed the intervention effect by SES.
In the Cretan study by Manios and Kafatos, the positive effect of their intervention was ascribed to the high degree of parent involvement, and to the provision of 'heart-healthy' alternatives in the intervention school tuck shops ${ }^{(45)}$. The introduction of school canteens was the main dietary intervention in the present study; however, we cannot separate the effects related to the use of canteens from those of parental involvement, or the fact that the municipality of Ballerup decided to focus on health, in general. Furthermore, we have no information on how many children had actually used the school canteens, and so we are not able to evaluate the effects on this. A process evaluation showed that in 2004, only seven of the ten intervention schools had a school canteen established ${ }^{(19)}$. Also, most servings in the school canteens were snacks rather than meals, and as modifications were made by some of the schools in the meals served, compared with the recipes originally provided ${ }^{(19)}$, the meals might not have been as healthy as intended. Therefore, the introduction of school canteens probably cannot solely explain the intervention effects observed in the present study.

We cannot deny that our findings, in part, may be explained as a regression towards the mean phenomena, where children of mothers with a short education have more room for improvement due to their worse eating habits pre-intervention. However, no differences were observed in the dietary intake pre-intervention across the levels of maternal education, except for the intake of dietary fibre ( $\mathrm{g} / \mathrm{MJ})$, for which a higher intake was observed with increasing maternal education in the intervention group. Moreover, the analyses were adjusted for pre-intervention intake and stratified by maternal education level. Thus, regression towards the mean is a less likely explanation for the findings.

The observed increased intake of dietary fibre $(\mathrm{g} / \mathrm{d})$ among the children of mothers with a short education in the intervention group was attenuated when the intake of dietary fibre was examined relative to the total energy intake. This finding indicates that total energy intake is a confounder or a mediating factor since the increased intake of dietary fibre is a consequence of the overall higher energy intake. Also, the 
intake of dietary fibre (g/d) among children of mothers with a short education in the comparison group seemed to decrease from pre- to post-intervention; and it may be due to the overall lower energy intake reported in that group, since the intake of dietary fibre in $\mathrm{g} / \mathrm{MJ}$ did not change.

Limitations are related to self-reported dietary intake such as under-reporting $^{(47,48)}$, recall bias $^{(47)}$, social desirability bias $^{(47,49)}$ and, particularly for this age group, parent's limited knowledge about the child's dietary intake, especially during the time spent away from home ${ }^{(47)}$. However, since Danish children, and particularly the young children, generally bring packed lunch boxes to school ${ }^{(50)}$, parents often have reasonable knowledge of the children's dietary intake during the school hours. Also, the reported dietary intake in the present study corresponds well with the intakes among children (aged 4-9 years) from the Danish National Survey from 2000 to $2004^{(6)}$. The 7-d food record enabled analyses at the individual level, and the objectively measured physical activity level also enabled an evaluation of the reported total energy intake. An increased knowledge on health during the study period could have resulted in parents reporting a healthier dietary intake post-intervention, which would have inflated the observed effects of the intervention. Also, it should be kept in mind that the dietary intake was calculated using standard recipes and food portion sizes, which might have influenced the results, especially when assessing the change in intake.

The percentages of under-reporters were higher post-intervention than pre-intervention, which is in line with an increasing under-reporting with increasing age, which has been reported in other studies, including Danish children and adolescents $^{(24,25)}$. When the intervention effect was examined including children who were assessed as acceptable reporters, only the increased intake of dietary fibre $(\mathrm{g} / \mathrm{d})$ observed among the children of mothers with a short education and the decreased intake of SFA (E\%) observed among the children of mothers with a long education remained borderline significant and significant, respectively. These latter results may be assumed to be more valid than the overall results. However, limitations are related to estimation of total energy expenditure and thus to the evaluation of the dietary intake as well. This is one more reason why the results of the dietary evaluation should be interpreted with caution. Thus, the observed effect may be influenced by under-reporting as our analysis among acceptable reporters revealed a borderline effect on dietary fibre intake, but still the strength of the association remained at the same degree.

More under-reporters were observed among children of mothers with short and medium educations post-intervention compared with those with a long education. That may strengthen the present results, since assuming that the children of mothers with a short education have under-reported their energy intake more than the other children, we would expect the intake of dietary fibre $(\mathrm{g} / \mathrm{d})$ to be lower as well. However, no difference in misreporting was observed between the intervention and comparison groups. Moreover, the evaluation was solely based on the total energy intake and did not provide information about selective misreporting.
Unfortunately, a substantial part of the invited children and their parents did not participate in the study, and especially for the dietary assessment, a low participation rate was obtained. This might have introduced some selection bias and resulted in insufficient power to detect differences between the two groups. If eating habits of overweight/obese children are more difficult to change, the lower BMI among the participants compared with non-participants and children not included in the analyses could have led to overestimated effects of the intervention. Also, the children and parents that chose to participate in the study might have been different from those not participating, and might have been more receptive to the intervention. Therefore, the results could have been affected by a selection bias, and might not be generalisable to Danish children overall, or to the initially invited study population. This may especially be the case for children of mothers with a short education where we mainly observed the intervention effects. However, as no difference was observed in BMI and physical activity pre-intervention between the children of mothers with a short education included and not included in the analyses, differences in health behaviours between those included and those not included in the analyses may, in fact, be limited.

We cannot completely eliminate that health-promoting activities were introduced in the comparison group during the 3 years of intervention, as this was not registered systematically. However, from an interview with the Deputy Head of the School Administration in Tårnby in 2005 by Husby I, we came to know that a school milk programme was introduced during the intervention period at the schools in Tårnby offering free milk $(250 \mathrm{ml} / \mathrm{d})$ for children in pre-school to seventh grade. To the knowledge of the Deputy Head, no other systematic changes regarding physical activity or dietary intake (e.g. implementation of school canteens) were established during the period (personal interview by Husby I of Jensen I, Deputy Head of the Public School Administration in Tånby; 4 March 2005). Moreover, pre-intervention measures were collected during the school-year when the intervention was initiated, and were thus not pre-intervention measures as such. Both these factors, in worst case, could have attenuated the effect of intervention in the present study.

It cannot be denied that some of the effect of the intervention observed in the present study might have been caused by multiple comparisons that could have increased the risk of type I error $^{(51)}$. When corrected for this using the Bonferroni $\operatorname{method}^{(52)}$, none of the results would remain significant. The Bonferroni method has, however, been criticised for being too conservative and increase the risk of type 2 errors ${ }^{(53,54)}$. Also, in the twenty-seven analyses conducted when stratified by maternal education, only one finding should be expected to occur by chance. Moreover, the fact that the results are all in the same direction makes it unlikely that the findings in the present study are caused by chance alone.

This multi-component school-based intervention resulted in changes or trends towards changes in the intake of dietary fibre $(\mathrm{g} / \mathrm{d})$, protein $(\mathrm{E} \%)$, fat $(\mathrm{E} \%)$ and $\mathrm{SFA}(\mathrm{E} \%)$ that were seen mainly among children of mothers with a short education. Even though we cannot determine which parts of 
intervention were effective, the study implies that the general focus on, and the prioritising of health in the municipality appeared to change the dietary intake in a more healthy direction among the children of mothers with a short education. These results are encouraging and indicate that school-based interventions may be a way to reach children from low SES families in the future. Due to cultural variations and differences in school systems, the intervention may, however, be most applicable to a Danish context. The changes in the dietary intake were generally modest. Based on the dietary intake findings observed among the children, future studies should aim at reducing the intake of fat, and preferably the intake of added sugar, as well.

\section{Acknowledgements}

The present study was supported by TrygFonden, Centre for Intervention Research in Health Promotion and Disease Prevention (formerly Centre for Applied Research in Health Promotion and Prevention) (B. W. J., B. L. H., L. B. A., A. B. and B. E.-N.); The Danish Heart Foundation (B. W. J., grant no. 10-04-R79-A2844-22578; A. B., project no. 11297 and L. B. A.); the 'Familien Hede Nielsen' foundation (B. W. J.); University of Southern Denmark (B. W. J.); Helsefonden (L. B. A.) and GENDINOB (B. M. N., grant no. 09-067111). TrygFonden, The Danish Heart Foundation, the 'Familien Hede Nielsen' foundation, Helsefonden and GENDINOB had no role in the design and analysis of the study or in the writing of this article.

The authors' contributions are as follows: The study was designed by B. L. H., B. E.-N., A. B. and I. H.; L. B. A. participated in the data collection; B. W. J. and L. M. v. K. analysed the data; $\mathrm{B}$. W. J. wrote the manuscript with supervision from B. M. N., E. T., I. H. and B. L. H. All the authors read and approved the final manuscript.

I. H. is in the board of the Arla Foundation. However, the Arla Foundation had no role in the design and analysis of the study or in the writing of this article. The authors have no conflicts of interest to declare.

\section{References}

1. Ebbeling CB, Pawlak DB \& Ludwig DS (2002) Childhood obesity: public-health crisis, common sense cure. Lancet 360, 473-482.

2. Reilly JJ (2005) Descriptive epidemiology and health consequences of childhood obesity. Best Pract Res Clin Endocrinol Metab 19, 327-341.

3. Mølgaard C, Dela F, Froberg K, et al. (2007) Forebyggelse af overvaegt blandt børn og unge - oplaeg til strategi (Prevention of Obesity among Children and Adolescents-proposal for a Strategy). Denmark: The Danish Nutritional and Physical Activity Council.

4. Shrewsbury V \& Wardle J (2008) Socioeconomic status and adiposity in childhood: a systematic review of cross-sectional studies 1990-2005. Obesity (Silver Spring) 16, 275-284.

5. Nordic Council of Ministers (2004) Nordic Nutritional Recommendations - Integrating Nutrition and Physical Activity, 4th ed. Copenhagen: Nordic Council of Ministers.

6. Pedersen AN, Fagt S, Groth MV, et al. (2010) Danskernes kostvaner 2003-2008 - Hovedresultater (Dietary Habits in
Denmark 2003-2008 - Main Results). Søborg: National Food Institute, Technical University of Denmark.

7. World Health Organization (2003) Diet, Nutrition and the Prevention of Chronic Disease. Report of a Joint WHO/FAO Expert Consultation no. 916. Geneva: World Health Organization.

8. Cribb VL, Jones LR, Rogers IS, et al. (2011) Is maternal education level associated with diet in 10-year-old children? Public Health Nutr 14, 2037-2048.

9. Han E \& Powell LM (2013) Consumption patterns of sugarsweetened beverages in the United States. J Acad Nutr Diet 113, 43-53.

10. Jones LR, Steer CD, Rogers IS, et al. (2010) Influences on child fruit and vegetable intake: sociodemographic, parental and child factors in a longitudinal cohort study. Public Health Nutr 13, 1122-1130.

11. Øverby NC \& Andersen LF (2002) Ungkost-2000, Landsomfattende kostholdsundersøkelse blant elever $i$ 4.-og 8. klasse $i$ Norge (Youth Diet-2000, A National Dietary Survey among Students from 4th and 8th Grade in Norway). Oslo: The Norwegian Directorate of Health, Department for Nutrition.

12. Stea TH, Overby NC, Klepp KI, et al. (2012) Changes in beverage consumption in Norwegian children from 2001 to 2008. Public Health Nutr 15, 379-385.

13. Rasmussen M \& Due P (editors) (2011) Skolebørnsundersøgelsen 2010 The School Children Study 2010. Copenhagen: National Institute of Public Health, University of Southern Denmark.

14. Groth MV, Christensen LM, Knudsen VK, et al. (2013) Sociale forskelle, børns kostvaner, fysisk aktivitet og overvagt, og voksnes kostvaner (Social Differences in Children's Dietary Habits, Physical Activity an Overweight and Adult's Dietary Habits). Søborg: National Food Institute, Technical University of Denmark.

15. Wechsler H, Devereaux RS, Margarett D, et al. (2000) Using the school environment to promote physical activity and healthy eating. Prev Med 31, s121-s137.

16. Van Cauwenberghe E, Maes L, Spittaels H, et al. (2010) Effectiveness of school-based interventions in Europe to promote healthy nutrition in children and adolescents: systematic review of published and 'grey' literature. Br J Nutr $\mathbf{1 0 3}$, $781-797$.

17. Hasselstrom HA, Karlsson MK, Hansen SE, et al. (2008) A 3-year physical activity intervention program increases the gain in bone mineral and bone width in prepubertal girls but not boys: the prospective Copenhagen School Child Interventions Study (CoSCIS). Calcif Tissue Int 83, 243-250.

18. Andersen LB \& Froberg K (2006) Sundhedsmassige aspekter affysisk aktivitet hos børn - et treårigt forsøg $i$ to kommuner ved København: Ballerup og Tårnby (Health Related Aspects of Physical Activity in Children - A Three Year Study in Two Copenhagen Municipalities: Ballerup and Tårnby). Copenhagen: Danish Health and Medicines Authority.

19. Husby I (2008) Børns mad, mellemåltider og hovedmåltider - i et folkesundhedsperspektiv (Children's food, snacks and meals - in a public health perspective). Ph.D thesis, Faculty of Health Science, University of Copenhagen

20. van Vught AJ, Heitmann $\mathrm{BL}$, Nieuwenhuizen $\mathrm{AG}$, et al. (2010) Association between intake of dietary protein and 3 -year-change in body growth among normal and overweight 6-year-old boys and girls (CoSCIS). Public Health Nutr 13, 647-653.

21. Fagt S, Biltoft-Jensen A, Matthiessen J, et al. (2008) Danskernes kostvaner 1995-2006. Status og udvikling med 
fokus på frugt og grønt samt sukker (Dietary Habits of Denmark 1995-2006. Status and Development with Focus on Fruits, Vegetables and Added Sugar). Søborg: National Food Institute, Technical University of Denmark.

22. Fagt S, Matthiessen J, Biltoft-Jensen A, et al. (2004) Udviklingen $i$ danskernes kost 1985-2001. Med fokus på sukker og alkohol samt motivation og barrierer for sund livsstil (The Development of the Danes' Diet 1985-2001. Focusing on Sugar and Alcohol and Motivation and Barriers for Healthy Lifestyle). Søborg: Danish Food and Veterinary Research Danmarks, Department for Nutrition.

23. Larsen BL (1994) Objektiv validering af kostdagbog til brug ved nationale kostundersøgelser (Objective Validation of Food Diaries Used a National Dietary Surveys). Copenhagen: Institute of Human Nutrition, The Royal Veterinary and Agricultural University.

24. Trolle E, Amiano P, Ege M, et al. (2011) Evaluation of $2 \times 24-\mathrm{h}$ dietary recalls combined with a food-recording booklet, against a 7-day food-record method among schoolchildren. Eur J Clin Nutr 65, Suppl. 1, S77-S83.

25. Rothausen BW, Matthiessen J, Groth MV, et al. (2012) Comparison of estimated energy intake from $2 \times 24$-hour recalls and a seven-day food record with objective measurements of energy expenditure in children. Food Nutr Res $\mathbf{5 6}$.

26. Saxholt E, Christensen AT, Møller A, et al. (2008) Fødevaredatabanken, version 7 (The Food Composition Table, Version 7). Søborg: National Food Institute, Technical University of Denmark.

27. DTU Food (2009) Danish Food Composition Databank ed.7.01. http://www.foodcomp.dk/v7/fvdb_search.asp (accessed August 2011).

28. Eiberg S, Hasselstrom HA, Gronfeldt V, et al. (2005) Maximum oxygen uptake and objectively measured physical activity in Danish children 6-7 years of age: the Copenhagen School Child Intervention Study. Br J Sports Med 39, 725-730.

29. Cole TJ, Bellizzi MC, Flegal KM, et al. (2000) Establishing a standard definition for child overweight and obesity worldwide: international survey. BMJ 320, 1240-1243.

30. Schofield WN (1985) Predicting basal metabolic rate, new standards and review of previous work. Hum Nutr Clin Nutr 39, Suppl. 1, 5-41.

31. Jensen BW, Nielsen BM, Husby I, et al. (2013) Association between sweet drink intake and adiposity in Danish children participating in a long-term intervention study. Pediatr Obes 8, 259-270.

32. Bugge A, El-Naaman B, Dencker M, et al. (2012) Effects of a 3-year intervention: The Copenhagen School Child Intervention Study. Med Sci Sports Exerc 44, 1310-1317.

33. Moreira P, Santos S, Padrao P, et al. (2010) Food patterns according to sociodemographics, physical activity, sleeping and obesity in Portuguese children. Int J Environ Res Public Health 7, 1121-1138.

34. Northstone K \& Emmett P (2005) Multivariate analysis of diet in children at four and seven years of age and associations with socio-demographic characteristics. Eur J Clin Nutr 59 $751-760$

35. Vereecken CA, Keukelier E \& Maes L (2004) Influence of mother's educational level on food parenting practices and food habits of young children. Appetite 43, 93-103.

36. Rogers I \& Emmett P (2003) The effect of maternal smoking status, educational level and age on food and nutrient intakes in preschool children: results from the Avon
Longitudinal Study of Parents and Children. Eur J Clin Nutr 57, 854-864.

37. Dupont WD \& Plummer J (1990) Power and sample size calculations: a review and computer program. Control Clin Trials 11, 116-128.

38. Dupont WD \& Plummer J (1998) Power and sample size calculations for studies involving linear regression. Control Clin Trials 19, 589-601.

39. Caballero B, Clay T, Davis SM, et al. (2003) Pathways: a school-based, randomized controlled trial for the prevention of obesity in American Indian schoolchildren. Am J Clin Nutr 78, 1030-1038.

40. Gortmaker SL, Cheung LW, Peterson KE, et al. (1999) Impact of a school-based interdisciplinary intervention on diet and physical activity among urban primary school children: eat well and keep moving. Arch Pediatr Adolesc Med 153, 975-983.

41. Gortmaker SL, Peterson K, Wiecha J, et al. (1999) Reducing obesity via a school-based interdisciplinary intervention among youth: Planet Health. Arch Pediatr Adolesc Med 153, 409-418.

42. Haerens L, Deforche B, Maes L, et al. (2006) Evaluation of a 2 -year physical activity and healthy eating intervention in middle school children. Health Educ Res 21, 911-921.

43. Kristjansdottir AG, Johannsson E \& Thorsdottir I (2010) Effects of a school-based intervention on adherence of 7-9year-olds to food-based dietary guidelines and intake of nutrients. Public Health Nutr 13, 1151-1161.

44. Luepker RV, Perry CL, McKinlay SM, et al. (1996) Outcomes of a field trial to improve children's dietary patterns and physical activity. The Child and Adolescent Trial for Cardiovascular Health. CATCH collaborative group. JAMA $\mathbf{2 7 5}$, $768-776$.

45. Manios Y \& Kafatos A (1999) Health and nutrition education in elementary schools: changes in health knowledge, nutrient intakes and physical activity over a six year period. Public Health Nutr 2, 445-448.

46. Vandongen R, Jenner DA, Thompson C, et al. (1995) A controlled evaluation of a fitness and nutrition intervention program on cardiovascular health in 10- to 12-year-old children. Prev Med 24, 9-22.

47. Livingstone MB, Robson PJ \& Wallace JM (2004) Issues in dietary intake assessment of children and adolescents. $\mathrm{BrJ}$ Nutr 92, Suppl. 2, S213-S222.

48. Magarey A, Watson J, Golley RK, et al. (2010) Assessing dietary intake in children and adolescents: considerations and recommendations for obesity research. Int $J$ Pediatr Obes 6, 2-11.

49. Livingstone MB \& Robson PJ (2000) Measurement of dietary intake in children. Proc Nutr Soc 59, 279-293.

50. Fagt S, Christensen T, Groth MV, et al. (2007) Børn og unges måltidsvaner 2000-2004 (Eating Habits among Children and Adolescents 2000-2004). Søborg: National Food Institute, Technical University of Denmark.

51. Feise RJ (2002) Do multiple outcome measures require $P$-value adjustment? BMC Med Res Methodol 2, 8.

52. Bland JM \& Altman DG (1995) Multiple significance tests: the Bonferroni method. BMJ 310, 170.

53. Bender R \& Lange S (2001) Adjusting for multiple testingwhen and how? J Clin Epidemiol 54, 343-349.

54. Sainani KL (2009) The problem of multiple testing. $P M R \mathbf{1}$, 1098-1103. 